\title{
The determinants of coping with pain in chronically ill geriatric patients - the role of a sense of coherence
}

\author{
Anna Andruszkiewicz' \\ Małgorzata Anna Basińska ${ }^{2}$ \\ Mirosława Felsmann ${ }^{3}$ \\ Mariola Banaszkiewicz ${ }^{4}$ \\ Alicja Marzec ${ }^{3}$ \\ Kornelia Kędziora- \\ Kornatowska ${ }^{5}$ \\ 'Department of Health Promotion, \\ Faculty of Health Sciences, Nicolaus \\ Copernicus University Ludwik \\ Rydygier Collegium Medicum, \\ ${ }^{2}$ Department of Psychopathology \\ and Clinical Diagnosis, Institute \\ of Psychology, Kazimierz Wielki \\ University, ${ }^{3}$ Department of Nursing, \\ ${ }^{4}$ Department of Postgraduate \\ Education, ${ }^{5}$ Department and \\ Clinic of Geriatrics, Faculty \\ of Health Sciences, Nicolaus \\ Copernicus University Ludwik \\ Rydygier Collegium Medicum, \\ Bydgoszcz, Poland
}

This article was published in the following Dove Press journal:

Clinical Interventions in Aging

9 February 2017

Number of times this article has been viewed

Background: Given the rising population of the elderly in modern societies, the concern for their good functioning poses a challenge for the 21 st century medicine and social services. Senior citizens are at an increased risk of developing chronic conditions, which in turn increase discomfort associated with physiological processes of aging. Sensations of pain have a particular influence on the mentioned discomfort, and pain is prevalent among older people. Therefore, from the perspective of an elderly person and senior care, it is crucial to identify determinants of effective coping with chronic pain.

Objectives: The aim of the research was to assess the relationship between a sense of coherence (SOC) and pain-coping strategies in chronically ill seniors. A total number of 188 individuals were included in the study, of whom 117 were female subjects and 71 were male subjects, with a mean age of 68.38 (standard deviation $[\mathrm{SD}]=6.35$ ) years in the studied group. Subjects were sampled based on a diagnosis of a chronic medical illness with chronic pain as one of the major symptoms.

Methods: The Polish adaptation of the Orientation to Life Questionnaire (SOC-29) to assess an SOC, the Coping Strategies Questionnaire (CSQ) to assess pain-coping strategies, and the visual analog scale (VAS) to assess pain intensity were used in the study.

Results and conclusion: The mean score of respondents' SOC was 133.44 (SD =24.35). Among most common pain-coping strategies used by the respondents were prayer and hope, and the declaration of coping with pain while redefining pain was the least often used coping strategy in the studied group. Individuals with stronger SOC were less prone to catastrophizing and more often declared that they were coping with and could control and reduce pain.

Keywords: chronic pain, pain-coping strategies, sense of coherence, older persons

\section{Introduction}

It is expected that by the mid-21st century, the number of people in their 60 s and older will constitute $25 \%$ of the world's population, with most noticeable increase occurring in developing countries, according to reports. This in turn will increase the number of chronic diseases and accompanying problems. ${ }^{1,2}$ Aging is characterized by deterioration of health caused by chronic diseases that are frequently accompanied by chronic pain, a highly prevalent sensation among older persons. A multicenter study carried out in the UK showed that the prevalence of pain in people older than 60 years was $50 \% .{ }^{1}$ Similar results were obtained in the PolSenior project in Poland where individuals aged 65 years and over experienced chronic pain more often than those aged 55-59 years. ${ }^{3}$

Recent years showed a dynamic increase in research into pain not only in the field of clinical medicine but also in nursing, psychology and neurophysiology. Pain is not
Correspondence: Mirosława Felsmann Department of Nursing, Faculty of Health Sciences, Nicolaus Copernicus University Ludwik Rydygier Collegium Medicum, Łukasiewicza I Street,

Bydgoszcz 85-82I, Poland

Tel +4852585 5805

Email miroslawa.felsmann@cm.umk.pl hy
hereby accept the Terms. Non-commercial uses of the work are permitted without any further permission from Dove Medical Press Limited, provided the work is properly attributed. For permission for commercial use of this work, please see paragraphs 4.2 and 5 of our Terms (https://www.dovepress.com/terms.php).
forition 
a simple reflex behavior but a complex phenomenon with varied dynamics that is affected by central nervous system mechanisms and psychological factors. ${ }^{4}$

It should be noted that pain is not a natural component of the aging process, a notion stressed for many years by the American Geriatric Society. 5,6 Pain in older people is very often not treated at all or insufficiently treated, and this, as research shows, significantly impairs functioning of individuals in this age group in various areas. It impairs cognitive functions, leads to mood changes (increases anxiety and depression), deepens social withdrawal, disturbs sleep and increases disability and the risk of falling down, which in turn result in lower quality of life. ${ }^{7-11}$

Researchers suggest that there are age-related differences in which people perceive and respond to pain. They believe that pain threshold in older people is higher, and therefore older people can bear more extreme stimuli at which pain begins to be felt. ${ }^{12}$ Researchers associate the underlying reason of those changes with the number of sensory receptors shrinking with age. Research findings regarding pain perception are not clear-cut. Some researchers claim that the underlying reason for lower pain sensitivity shall be linked to the changes that accompany the aging process, eg, structural, biochemical and functional changes in the peripheral nervous system and the reduction of myelinated and unmyelinated fibers as well as more frequent neuronal degeneration and impaired functioning of neurons. There is also a reduced concentration of neurotransmitters known to be involved in nociceptive sensation. ${ }^{13}$ All things considered, issues associated with pain sensations among older people have yet to be clarified. There are many ethical and methodological problems associated with pain research, ranging from the issue of inflicting pain to having an objective measure of such a subjective sensation as pain. ${ }^{14}$ Some researchers believe that the number and type of factors affecting pain perception in old people differ significantly from those in younger individuals. And thus, it is more difficult to group them. ${ }^{15,16}$

Based on the basic criterion of pain classification, ie, duration of pain, we distinguish acute pain and chronic pain. A significant factor differentiating acute pain from chronic pain is that the former is a symptom of a disease, while chronic pain is a condition itself and shall be treated as a separate condition, irrespective of the reason. ${ }^{17,18}$

Chronic pain is caused by different mechanisms than acute pain, and therefore it activates a complex process of physical and psychosocial changes in the organism ${ }^{19}$ that are mostly controlled by brain processes. ${ }^{20}$

In most patients, chronic pain activates mechanisms that reduce their quality of life: psychological, physiological and social impairments. Those mechanisms depend upon the duration and intensity of pain, not the underlying cause of pain. In chronic pain patients, no stimulation of the sympathetic nervous system and secretory system can be observed, which is common in acute pain. Instead of mental stimulation and anxiety, depression and excessive irritability and nervousness occur. Chronic pain has numerous adverse consequences in every area of life (social, occupational and family). Growing pain can contribute to social isolation, which in turn leads to solitude. Uncontrolled chronic pain can also affect spiritual life, leading to a sense of regret, despair, the loss of the meaning of life and a feeling of being forsaken by all, including god. Moreover, pain impairs cognitive functioning, leading, in most cases, to impaired short-term memory, attention deficits, impaired thinking and decision making as well as difficulties in reading with understanding and expressing themselves. ${ }^{21}$

Pain, and in particular chronic pain, is a stressful factor for an individual. It destroys their psychological balance forcing them to find appropriate coping strategies. The following two major coping strategies with disease-related pain can be pointed out:

1. Task-based approach to problem-solving, making an effort to change/eliminate the source of stress. The patient is focused on maintaining life activity, diverting his/her attention away from pain and undertaking exercises and efforts meant to diminish pain.

2. Emotion-focused coping strategies, the aim of which is to regulate/reduce unpleasant emotional reactions. In this case, a patient strives to seek support and avoid physical activity and passiveness. ${ }^{22,23}$

It is believed that task-based coping strategies are likely to be more effective because they focus specifically on solving pain-related problems, for instance, health improving exercises, and also involve seeking for information that might be used to improve the situation, ${ }^{23}$ whereas emotionfocused coping strategies are to reduce or relieve negative emotions (through withdrawal, repression and denial as avoidance strategies $)^{24}$ and as a result lead to alcohol and substance abuse. ${ }^{25}$

Some patients employ ineffective coping strategies, trying to run away from the problem, pretending it does not exist. Or just the opposite, they focus on the problem and consider it to be a catastrophe, which adds to their suffering and does not bring about the expected results of the treatment. ${ }^{23}$

Advances in psychoneurology and health psychology have led to the development of research into personality components, which have a modifying function with reference to risk factors and help adapt to a disease and cope with the disease 
and its consequences, including pain. These factors are called personal resources, as opposed to deficits that impair response to stress and diminish the effectiveness of coping. ${ }^{26}$ In health psychology, they are also called health potentials.

Therefore, resources are elements that protect an individual and may be used to meet their needs, aspirations and goals and counter negative consequences of stress. They also help individuals cope with a difficult situation. ${ }^{27,28}$ These include a sense of coherence (SOC), which is crucial in maintaining health according to the author of the construct. ${ }^{29}$

As Antonovsky said, "SOC is a global orientation that expresses the level of a human having a profound confidence of stimuli coming during life are stable and predictable. There are also resources that help meeting requirements and these are worth involvement". ${ }^{29}$

$\mathrm{SOC}$ is a complex variable with the following three major components: comprehensibility, manageability and meaningfulness. SOC as a personality variable affects individuals' functioning in different areas of their life and, as research has shown, in a varied and positive way, both directly and indirectly impacting their health. Individuals with strong SOC are in better mental and physical condition, ${ }^{30-32}$ are more likely to engage in physical activity, fulfill the given tasks, are capable of maintaining intimate relationships with other individuals ${ }^{33}$ and more readily accept unavoidable difficulties in their life. ${ }^{34}$ They have a higher level of satisfaction with life and a higher quality of life score. ${ }^{35,36}$ SOC plays a very important role in emotional coping with the challenges posed by the disease, ${ }^{37,38}$ encourages better functioning at work and prevents a burnout syndrome. ${ }^{39-41}$ The analysis of data obtained from 5,000 respondents led Larson ${ }^{42}$ to concluded that there is a strong correlation between SOC and healthy behavior, subjective evaluation of health and quality of life.

It should be remembered that pain mechanism is a multifaceted phenomenon. Therefore, the International Association for the Study of Pain recommends an interdisciplinary treatment for chronic pain with a particular attention given not only to somatic aspects but also to psychological aspects. It is known that pharmacotherapy remains the primary therapeutic method, yet it should only be a part of the treatment process, the outcome of which is to reduce pain intensity and also to improve the patient's quality of life and his/her coming back to normal family and social life. ${ }^{43}$

In the therapeutic process, specific consideration should be given to an individual's resources that can affect functioning during illness. This behavior may shape functioning in the other direction as it would appear from specific disease.
The following research questions were formulated in the study:

1. What is the intensity of pain in the studied group and the relationship between subjects' daily activity and pain intensity?

2. What is the level of SOC in the studied group?

3. What are coping strategies with pain employed by older patients with chronic diseases?

4. Is there a relationship between the SOC and coping strategies with pain in the studied group?

\section{Methods}

\section{Sample characteristics}

A total number of 188 individuals were included in the study, of whom $117(62 \%)$ were female subjects and 71 (38\%) were male subjects. The mean age of the study sample was 68.38 (standard deviation $[\mathrm{SD}]=6.35$ ) years. The youngest individual was aged 60 years, and the oldest individual was aged 89 years. Male (mean $[\mathrm{M}]=68.35 ; \mathrm{SD}=5.99$ ) and female $(\mathrm{M}=68.40 ; \mathrm{SD}=6.58)$ subjects were of similar age. Most subjects completed secondary education (58 individuals; $31.02 \%$ ) and vocational education (47 individuals; $25.13 \%$ ), with the least number of subjects having higher education diploma (30 individuals; $16.04 \%$ ). All subjects had a diagnosis of a chronic medical illness with pain as a major symptom. Most of them suffered from osteoporosis and rheumatoid arthritis (123 individuals; 68\%) and vascular disease (47 individuals; $20.74 \%$ ), while the least number of patients suffered from slipped disk (four individuals; 4.26\%).

The criteria in order to be included in the research were as follows: diagnosed with a chronic disease in which pain is the main symptom, lack of cognitive disorder that could preclude self-assessment of pain and answering the questionnaire.

\section{Methods and study measures}

The following standardized measures were used in the study.

\section{The Polish adaptation of the Orientation to Life Questionnaire (SOC-29)}

This scale was developed by Antonovsky to assess SOC. The SOC-29 questionnaire consists of 29 statements. Each statement is rated on a 7 -item scale (ranging from 1 to 7 ) with the extreme items on the scale described. The questionnaire has the following three subscales corresponding to the three components of SOC: comprehensibility (11 statements), manageability (10 statements) and meaningfulness (eight statements). The total score is calculated on the basis of specific keys that allow assessing the SOC and its three components. ${ }^{29}$ 
The Polish adaptation of the Orientation to Life Questionnaire (SOC-29) was developed in 1993 and is highly reliable. Internal consistency indicators calculated with a split-half method with Sperman-Brown correction were 0.92 for SOC, 0.78 for comprehensibility, 0.72 for manageability and 0.68 for meaningfulness, while Cronbach's alpha was $0.78 .{ }^{44}$

\section{The Coping Strategies Questionnaire (CSQ) for Pain} This scale was developed by Rosenstiel and Keefe ${ }^{45}$ and adapted by Juczyński. ${ }^{20}$ This questionnaire is used to assess ways of coping with pain and self-efficacy in managing and reducing pain among individuals who are adult, sick and suffering from pain. The questionnaire contains 42 statements that describe various ways of coping with pain and two questions regarding self-assessment of pain-coping and pain-alleviating strategies. ${ }^{20}$

Ways of coping with pain reflect six cognitive strategies and one behavioral strategy, which in turn are themselves part of the following three components: cognitive coping, distracting attention and undertaking alternative activities and catastrophizing and seeking hope. The structure of the strategies defined in the questionnaire allows them to be examined in the context of:

- active coping (reevaluating the pain, ignoring the pain and declaring to cope with the pain),

- distraction and undertaking alternative activities (distraction and increased behavioral activity),

- catastrophizing and seeking hope (catastrophic thinking, praying and having hope).

Research so far confirms that CSQ is a reliable and relevant instrument that allows prognostic strategies of adapting to chronic pain to be defined. It is also used to assess own skills in using various ways of coping with pain and alleviating pain strategies. ${ }^{46}$

\section{The visual analog scale (VAS) for pain}

This was used in the study to assess pain intensity with a score of 0 meaning "no pain" and a score of 10 meaning "worst imaginable pain".

\section{The structured interview}

This was used to collect demographic data and variables associated with functioning in the disease.

\section{Ethical conduct procedure}

The study was conducted in line with the principles stated in the Declaration of Helsinki. ${ }^{47}$ Permission to carry out the study was obtained from the Research Ethics Committee at
Nicolaus Copernicus University Ludwik Rydygier Collegium Medicum. The major criteria for the sample selection were a diagnosis of a chronic medical illness with chronic pain as one of the major symptoms and the written informed consent of a subject.

\section{Statistical analysis}

Statistical analysis was performed using STATISTICA 9.0 software. The level of statistical significance was set at 0.05 . A correlation model was used in the data analysis, and the following statistical tests were employed. In order to describe variables in the groups, the mean, the SD and percentage were used. In order to determine the direction and the strength of a correlation between variables, the sample Pearson correlation test (in the case of a linear correlation between variables and if the variables were quantitative in nature) was used, or if the variables were quantitative in nature or there was no linear correlation between the variables, the nonparametric Spearman's $R$ correlation test was utilized, and analysis of variance or the Kruskal-Wallis tests were used when certain conditions were not met followed by the test for the post hoc analysis of the identified differences in order to define the significance of differences between many mean values.

\section{Results \\ Pain assessment}

Patients assessed the intensity of pain they experienced and its effect on three areas of life, activity, mobility and mood, on a 10-point scale. All mean scores were in the average range, yet a maximum difference between the scores was noted (Table 1).

Negative effect of pain on patients' mood received the highest scores and was significantly different from the pain affecting patients' activity $(P=0.008)$ but was not different from the pain affecting patient's mobility $(P=0.187)$. There were slight differences between male and female subjects in how they assessed the effect of pain on different areas of their functioning, but these differences were not statistically significant.

Table I Descriptive statistics for pain experienced by older patients

\begin{tabular}{lllll}
\hline $\begin{array}{l}\text { Characteristics of pain } \\
\text { experienced by older patients }\end{array}$ & M & SD & Minimum & Maximum \\
\hline Assessment of pain & 5.74 & 2.21 & 1.00 & 10.00 \\
Effect of pain on daily activities & 5.54 & 2.59 & 1.00 & 10.00 \\
Effect of pain on mobility & 5.89 & 2.78 & 1.00 & 10.00 \\
Effect of pain on mood & 6.26 & 2.65 & 1.00 & 10.00 \\
Analgesics & 1.46 & 1.08 & 0.00 & 4.00 \\
\hline
\end{tabular}

Abbreviations: $M$, mean; SD, standard deviation. 
Table 2 The $M$ values and SD for pain experienced by female and male subjects

\begin{tabular}{|c|c|c|c|c|}
\hline \multirow[t]{2}{*}{$\begin{array}{l}\text { Characteristics of pain } \\
\text { experienced by older patients }\end{array}$} & \multicolumn{2}{|c|}{$\begin{array}{l}\text { Females, } \\
\mathbf{N}=117\end{array}$} & \multicolumn{2}{|c|}{$\begin{array}{l}\text { Males, } \\
\mathrm{N}=7 \text { I }\end{array}$} \\
\hline & M & SD & $\mathbf{M}$ & SD \\
\hline Assessment of pain & 5.90 & 2.29 & 5.49 & 2.04 \\
\hline Effect of pain on daily activities & 5.59 & 2.76 & 5.46 & 2.31 \\
\hline Effect of pain on mobility & 5.79 & 2.90 & 6.06 & 2.59 \\
\hline Effect of pain on mood & 6.08 & 2.81 & 6.55 & 2.35 \\
\hline Analgesics & 1.46 & 1.02 & 1.45 & 1.17 \\
\hline
\end{tabular}

Abbreviations: M, mean; SD, standard deviation.

The assessment of pain and its effect on various areas of functioning was similar in older male and female patients. The subjects under study (whole group) took an average of 1.45 analgesic tablets per day $(\mathrm{SD}=1.08)$, with most of them taking one to two tablets per day (Table 2).

\section{Average scores for subjects in the study}

Given the differences in the number of questions in the subscales, they cannot be compared. Significant difference can only be observed in scores within individual subscales (Table 3).

The intensity of SOC and its components was similar in older male and female patients. Subjects were divided into the following three groups regarding SOC: low, average and high intensity - adding or subtracting $0.5 \mathrm{SD}$. The subjects were roughly evenly distributed across the three groups (Table 4).

Praying, having hope and declarations of coping with pain were among the most often used coping strategies among patients in the study, while the reevaluation of pain sensations was the least often used strategy. Moreover, the subjects believed that they were able to control pain to a certain extent and reduce it although to a lesser extent (Table 5).

There were statistically significant differences in the intensity of some coping strategies used by male and female subjects (Table 6).

The following cognitive strategies of coping with pain sensations were significantly more often used by male

Table 3 Descriptive statistics regarding SOC in the study sample $(\mathrm{N}=188)$

\begin{tabular}{lllll}
\hline SOC & M & SD & Minimum & Maximum \\
\hline Comprehensibility & 46.21 & 10.84 & 17.00 & 74.00 \\
Meaningfulness & 39.52 & 8.60 & 16.00 & 56.00 \\
Manageability & 47.62 & 9.68 & 23.00 & 70.00 \\
SOC & 133.35 & 25.47 & 65.00 & 197.00 \\
\hline
\end{tabular}

Abbreviations: $M$, mean; SD, standard deviation; SOC, sense of coherence.
Table 4 Subjects distribution in numbers across subgroups regarding the level of SOC $(\mathrm{N}=187)$

\begin{tabular}{lllll}
\hline $\begin{array}{l}\text { Levels } \\
\text { of SOC }\end{array}$ & Number & $\begin{array}{l}\text { Cumulative } \\
\text { number }\end{array}$ & Percentage & $\begin{array}{l}\text { Cumulative } \\
\text { percentage }\end{array}$ \\
\hline Low & 66 & 66 & 35.29 & 35.29 \\
Average & 69 & 135 & 36.90 & 72.19 \\
High & 52 & 187 & 27.81 & 100.00 \\
Missing values & I & 188 & & \\
\hline
\end{tabular}

Abbreviation: SOC, sense of coherence.

subjects in coping with pain: reevaluation, ignoring sensations, and declaration of coping with pain. Moreover, they were more likely to use an avoidance strategy - distracting attention.

\section{SOC and pain assessment of pain-coping strategies}

The SOC showed statistically significant negative correlation with subjective assessment of the effect of pain on mood and taking medication (Table 7).

Patients with stronger SOC were more likely to assess pain as weaker and its effect on mood as lesser. These patients were also taking fewer analgesics. SOC showed statistically significant correlation with pain-coping strategies (Table 8).

Older chronically ill patients with stronger SOC were less likely to use a catastrophizing strategy and were more likely to declare that they were coping with pain. They also believed that they could control and reduce pain they experienced. Given the intensity of the SOC, statistically significant variation of coping strategies such as catastrophizing, declaration of coping with pain and the extent to which subjects could control it were identified (Table 9).

Individuals with high SOC were less likely to catastrophize $\left(M_{\mathrm{w}}=11.58\right)$, and this strategy was significantly less often used than in individuals with lower $\left(M_{\mathrm{N}}=17.15\right)$ and average

Table 5 Descriptive statistics regarding coping strategies with pain in the studied group

\begin{tabular}{lllll}
\hline $\begin{array}{l}\text { Strategies for coping } \\
\text { with pain }\end{array}$ & M & SD & Minimum & Maximum \\
\hline Distracting attention & 16.04 & 7.95 & 0.00 & 33.00 \\
Reevaluation of pain sensations & 10.12 & 8.19 & 0.00 & 30.00 \\
Catastrophizing & 15.37 & 7.73 & 0.00 & 34.00 \\
Ignoring sensations & 12.86 & 8.08 & 0.00 & 35.00 \\
Praying/having hope & 21.55 & 8.68 & 0.00 & 36.00 \\
Declarations of coping with pain & 19.44 & 7.97 & 0.00 & 36.00 \\
Increased behavioral activity & 17.14 & 7.82 & 0.00 & 35.00 \\
Pain control & 3.36 & 1.13 & 1.00 & 6.00 \\
Ability to reduce pain & 2.95 & 1.04 & 0.00 & 6.00 \\
\hline
\end{tabular}

Abbreviations: M, mean; SD, standard deviation. 
Table 6 Statistically significant differences between $M$ values for coping strategies in female and male subjects

\begin{tabular}{|c|c|c|c|c|c|c|}
\hline \multirow[t]{2}{*}{ Pain-coping strategies } & \multicolumn{2}{|c|}{ Females, $\mathbf{N}=\mathbf{I}$ I } & \multicolumn{2}{|c|}{ Males, N=7 I } & \multirow[t]{2}{*}{$t / z$} & \multirow[t]{2}{*}{$P$-value } \\
\hline & $\mathbf{M}$ & SD & $\mathbf{M}$ & SD & & \\
\hline Distracting attention (z) & 14.67 & 8.32 & 18.30 & 6.77 & -3.371 & 0.001 \\
\hline Reevaluation of pain sensations & 8.75 & 7.87 & 12.38 & 8.25 & -3.008 & 0.003 \\
\hline Catastrophizing & 14.60 & 7.64 & 16.63 & 7.76 & -1.761 & 0.080 \\
\hline Ignoring sensations & 11.62 & 7.96 & 14.90 & 7.91 & -2.744 & 0.007 \\
\hline Praying/having hope & 20.77 & 9.46 & 22.83 & 7.09 & -1.262 & 0.206 \\
\hline Declarations of coping with pain & 18.24 & 7.89 & 21.41 & 7.76 & -2.685 & 0.008 \\
\hline Increased behavioral activity & 16.41 & 8.27 & 18.35 & 6.90 & -1.658 & 0.099 \\
\hline Pain control & 3.32 & 1.09 & 3.42 & 1.19 & -0.557 & 0.578 \\
\hline Ability to reduce pain & 2.97 & 0.96 & 2.90 & 1.16 & 0.480 & 0.632 \\
\hline
\end{tabular}

Abbreviations: M, mean; SD, standard deviation.

$\left(M_{\mathrm{P}}=16.65\right)$ SOC. Individuals with low and average SOC differed from individuals with high SOC. The latter used mostly cognitive coping strategy - declaration of coping with pain $\left(M_{\mathrm{N}}=17.52 ; M_{\mathrm{P}}=18.91 ; M_{\mathrm{W}}=22.71\right)$.

Similar differences were observed in the extent to which the subjects could reduce pain they experienced. Patients with high SOC were mostly convinced that they could reduce pain $\left(M_{\mathrm{W}}=3.71\right)$ when compared with patients with both low and average $\operatorname{SOC}\left(M_{\mathrm{N}}=3.23\right.$ and $\left.M_{\mathrm{P}}=3.22 ; P=0.02\right)$.

\section{Discussion}

Pain experienced by people in old age still presents an interdisciplinary challenge. First, demographic data indicate that the number of people in old age is still on the rise. Second, these people often experience pain, which in most cases, is a chronic pain. Pain is a subjective experience, and its multidimensional nature has to be taken into consideration. In analyzing factors associated with pain experienced by older people, not only comorbidities and pharmaceuticals they take but also their mental state, coping mechanisms, beliefs about pain and ways of coping with the pain and also social support should be taken into consideration. ${ }^{48}$

The study results show that chronic pain has the greatest effect on a person's mood. Other studies on chronic pain experienced by older people have confirmed the same results. They have revealed that pain has significant effect on mood that is characterized by tension, anxiety and irritation. ${ }^{49}$
It turns out that depressed mood is more often diagnosed in chronic arthritis-related pain than in other conditions that cause less severe pain. Researchers from University of Pittsburg ${ }^{18,50}$ investigated the relationship between pain and depression, comparing different age groups. In the younger sample, a low or slight correlation between pain intensity and depression was found. Researchers from the Medical Center of Georgia assessed the effect of neuropsychiatric disorders and pain. The pain scores were highest in patients with depression. ${ }^{51}$

Besides taking pain-relieving medication, older people utilize various strategies to cope with chronic pain. These range from cognitive to behavioral strategies. There is also evidence supporting effective use of the so-called religious ways of coping with pain. ${ }^{52}$ In a cross-sectional research, religious and nonreligious pain-coping strategies used by older people were investigated. ${ }^{48}$ The results showed that these strategies were quite often used by both female and male individuals, but women were found to be more likely to use those strategies. The present study has yielded similar results. Prayer and having hope proved to be most often applied pain-coping strategies in the study sample. The study showed that women were more likely to use those strategies, while men used cognitive strategies, reevaluating or ignoring pain sensation.

The basic question posed in this study referred to the relationship between the level of the SOC and the employed pain-coping strategies. The abovementioned results show that individuals with stronger SOC take less medication, assess

Table 7 Correlation - Spearman's and Pearson's - between sense of coherence and subjective assessment of the effect of pain

\begin{tabular}{|c|c|c|c|}
\hline Pairs of variables & $\boldsymbol{R}$ & $r$ & $P$-value \\
\hline Sense of coherence and subjective assessment of pain & -0.216 & & 0.003 \\
\hline Sense of coherence and effect of pain on daily activity & -0.139 & & 0.058 \\
\hline Sense of coherence and effect of pain on mobility & -0.134 & & 0.068 \\
\hline Sense of coherence and effect of pain on mood & -0.214 & & 0.003 \\
\hline Sense of coherence and analgesics & & -0.256 & $<0.001$ \\
\hline
\end{tabular}


Table 8 Spearman's and Pearson's correlation between the SOC and pain-coping strategies

\begin{tabular}{lll}
\hline Pain-coping strategies & SOC & \\
\cline { 2 - 3 } & $\boldsymbol{R}$ & $\boldsymbol{P}$-value \\
\hline Distracting attention & 0.080 & 0.277 \\
Catastrophizing & -0.280 & $<0.00$ I \\
Praying/having hope & 0.060 & 0.416 \\
Declarations of coping with pain & 0.300 & $<0.00$ I \\
Increased behavioral activity & 0.060 & 0.414 \\
Ability to reduce pain & $0.18 \mathrm{I}$ & 0.014 \\
\hline & $\boldsymbol{r}$ & $\boldsymbol{P}$-value \\
\hline Reevaluation of pain sensations & 0.063 & 0.397 \\
Ignoring sensations & 0.110 & 0.136 \\
Internal control & 0.267 & $<0.00 \mathrm{I}$ \\
\hline
\end{tabular}

Abbreviation: SOC, sense of coherence.

pain as less severe pain has a lower effect on their mood. These individuals declared that they could control pain and have definitely less often catastrophizing thoughts. Therefore, we can conclude that the role of SOC as a buffer in the functioning of sick individuals has been confirmed by other independent researchers. ${ }^{53-55}$ As assumed by Antonovsky, individuals with stronger SOC have a better understanding of events and states they experience, can better select appropriate coping techniques to deal with them and most importantly give them a meaning. Such individuals are more physically able, show better cognitive, emotional and social functioning, have better subjective health, are less sensitive to problems associated with their disease and have lower anxiety levels, higher subjective quality of life (that also shows in higher scores in subscales of physical functioning), less intensive somatic symptoms and even greater satisfaction with their financial standing. ${ }^{36,56-58}$

\section{Conclusion}

The study results show that in providing care for older people with chronic pain, not only a multifaceted assessment of

Table 9 Variance analysis results - intensity of the SOC and the use of pain-coping strategies

\begin{tabular}{lll}
\hline Pain-coping strategies & $\boldsymbol{F}$ & P-value \\
\hline Distracting attention & 0.146 & 0.864 \\
Reevaluation of pain sensations & 0.114 & 0.892 \\
Catastrophizing & $9.84 \mathrm{I}$ & $<0.00 \mathrm{I}$ \\
Ignoring sensations & $\mathrm{I} .3 \mathrm{II}$ & 0.272 \\
Praying/having hope & $\mathrm{I} .120$ & 0.329 \\
Declarations of coping with pain & 6.849 & $0.00 \mathrm{I}$ \\
Increased behavioral activity & 1.224 & 0.296 \\
Pain control & 3.557 & $0.03 \mathrm{I}$ \\
Ability to reduce pain & 2.775 & 0.065 \\
\hline
\end{tabular}

Abbreviation: SOC, sense of coherence. somatic ailments is required, but it is also necessary to pay attention to individual resources. Hence, SOC seems to be particularly important as it helps the clinician select more constructive strategies to cope with the pain of the elderly.

Interrelationships between personal characteristics should be tested, as well as emotional functioning and the experienced pain in various somatic diseases.

Therapeutic education, including coping with pain, constitutes an important aspect in the care of older people suffering from chronic pain.

\section{Limitation of this study}

There are areas that require very intense educational activities of patients with chronic pain as our survey proves. However, the number of persons and the vast differentiation of the tested group require some caution when the results are being interpreted. Furthermore, a survey conducted in a correlation model limits the possibility to draw conclusions on its basis.

\section{Disclosure}

The authors report no conflicts of interest in this work.

\section{References}

1. Elliott AM, Smith BH, Penny KI, Smith WC, Chambers WA. The epidemiology of chronic pain in the community. Lancet. 1999;354(9186): $1248-1252$.

2. Michel JP, Newton J, Kirkwood BLT. Medical challenges of improving the quality of a longer life. JAMA. 2008;6:688-690.

3. Błędowski P, editor. Report PolSenior. Medical, psychological, sociological and economic aspects of ageing in Poland - research project 2007-2010. In: Mossakowska M, Więcek A, Błędowski P, editors. Analysis of Chronic Pain in Old People in Poland. 2011:295-307. Polish.

4. Melzac R, Wall P. The Challenge of Pain. London: Penguin Books Ltd; 1996.

5. AGS Panel on Persistent Pain in Older Persons. The management of persistent pain in older persons. J Am Geriatr Soc. 2002;50(6 Suppl): S205-S224.

6. American Geriatric Society. Panel on the pharmacological management of persistent pain in older persons: pharmacological management of persistent pain in older persons. $J$ Am Geriatr Soc. 2009;37(8):1331-1346.

7. Davis MP, Srivastava M. Demographics, assessment and management of pain in the elderly. Drugs Aging. 2003;20(1):23.

8. Pasero C, McCaffrey M. Pain control: comfort - function goals. A way to establish accountability for pain relief. Am J Nurs. 2004;104(9): $77-78,81$

9. Pasero C, Rakel B, McCaffery M. Pain in Older Persons. Seattle, Washington, DC: IASP; 2005.

10. Jensen MP, Turner JA, Romano JM. Changes after multidisciplinary pain treatment in patient pain beliefs and coping are associated with concurrent changes in patient functioning. Pain. 2007;131(1-2):38-47.

11. Sullivan M, Tanzer M, Stanish W, et al. Psychological determinants of problematic outcomes following total knee arthroplasty. Pain. 2009; 143(1-2):123-129.

12. Benedetti F, Vighetti S, Ricco C, et al. Pain threshold and tolerance in Alzheimer's disease. Pain. 1999;80:377-382. 
13. Pergolizzi J, Böger RH, Budd K, et al. Opioids and the management of chronic severe pain in the elderly: consensus statement of an international expert panel with focus on the six clinically most often used WHO step III opioids (buprenorphine, fentanyl, hydromorphone, methadone, morphine, oxycodone). Pain Pract. 2008;8(4):287-313.

14. Stuart-Hamilton I. The Psychology of Ageing. Poznan: Zysk i S-ka; 2006:34. Polish.

15. Corran TM, Farrell MJ, Helm RD, Gibson SJ. The classification of patients with chronic pain: age as a contributing factor. Clin J Pain. 1997; 13(3):207-214.

16. Mayer EA, Bushnell MC. Functional Pain Syndromes: Presentation and Pathophysiology. Seattle: IASP Press; 2009.

17. Schwob M. Pain. Katowice: Domino Książnica; 1999. Polish.

18. Turk DC, Melzack R. Handbook of Pain Assessment. New York, NY: Guilford Press; 2001:276-295.

19. Dobrogowski J, Wordliczek J. Pain Medicine. Warszawa: PZWL; 2004. Polish.

20. Juczyński Z. Perceived control and chronic pain coping strategies. Sztuka Leczenia. 2001;VII(2):9-16. Polish.

21. Eccleston C, Morley SJ, Williams AC. Psychological approaches to chronic pain management: evidence and challenges. Br J Anaesth. 2013; 111(1):59-63.

22. Trzebiatowska I, Majkowicz M, Zwaliński M, et al. Adaptation strategies to cancer disease (preliminary reports). Psychoonkologia. 1997;(1): 4-12. Polish.

23. de Walden-Gałuszko K. Psychological aspects and treatment of pain. Medycyna Paliatywna w Praktyce. 2007;1(2):66-70. Polish.

24. Juczyński Z, Chrostowska-Jabłońska B. Strategies of coping with cancer disease. Psychoonkologia. 1999;5:3-9. Polish.

25. Bishop GD. Health Psychology: Integrating Mind and Body. Wroclaw: ASTRUM; 2007:322-336. Polish.

26. Sęk H. Salutogenesis and functional properties of sense of coherence. In: Sęk H, Pasikowski T, editors. Health-Stress-Resources. Poznan: Foundation Humaniora; 2001:13-14. Polish.

27. Poprawa R. Personal resources in coping with stress. In: Dolińska D, Zygmunt G, editors. The Basics of Health Psychology. Wroclaw: University of Wroclaw; 2001:101-136. Polish.

28. Basińska MA. Patients' Mental Functioning in Selected Endocrine Diseases. Somatic and Personal Conditions. Bydgoszcz: Kazimierz Wielki University; 2009:45-47. Polish.

29. Antonovsky A. Unraveling the Mystery of Health. How People Manage Stress and Stay Well. Warsaw: Foundation IPN; 1995:125-153. Polish.

30. Drory Y, Florian V, Kravetz S. Sense of coherence: sociodemographic variables and perceived psychological and physical health. Psychologia. 1991;2(2):119-125.

31. Bowman BJ. Cross-cultural validation of Antonovsky's sense of coherence scale. J Clin Psychol. 1996;52(2):545-549.

32. Szymona K, Pawłowska B, Płotka A. Sense of coherence and sociodemographic factors in patients with neurosis. Public Health. 2002; 112(suppl):177-179. Polish.

33. Yeheskel A. The intimate environment and the sense of coherence among. Holocaust survivors. Soc Work Health Care. 1995;20(3):25-35.

34. Nordstrom G, Lutzen K. Acceptance of ostomy surgery: a Swedish pilot study. Scand J Caring Sci. 1995;9(1):11-15.

35. Pasikowski T. Stress and Health. Salutogenic Approach. Poznan: Foundation Humaniora; 2000:76-83. Polish.

36. Kozaka J. Quality of life and sense of coherence in women with ovarian cancer. Psychoonkologia. 2002;6:13-19. Polish.

37. Lundman B, Norberg A. The significance of a sense of coherence for subjective health in persons with insulin-dependent diabetes. $J A d v$ Nurs. 1993;18(3):381-386.
38. Agardh EE, Ahlbom A, Andersson T, et al. Work stress and low sense of coherence is associated with type 2 diabetes in middle-aged Swedish women. Diabetes Care. 2003;26(3):719-724.

39. Ogińska-Bulik N. Personal resources protecting police officers from negative consequences of occupational stress. In: Juczyński Z, Ogińska-Bulik N, editors. Personal and Social Resources Enhancing an Individual's Health. Lodz: University Lodz; 2003:91-106. Polish.

40. Basińska MA, Andruszkiewicz A. Sense of coherence as a predictor of healthy functioning in the workplace - a study on social workers. In: Wrona-Polańska H, editor. Health-Stress-Disease. Krakow: Oficyna Impuls; 2008:63-74. Polish.

41. Basińska MA, Andruszkiewicz A, Grabowska M. Nurses' sense of coherence and their work-related patterns of behaviour. Int J Occup Med Environ Health. 2011;24(3):1-11.

42. Larson G. Quality of life and health: impact of sense of coherence and view of life. Paper presented at: The 8th Conference of the European Health Psychology Society - Quality of life and health psychology; 1994; Alicante, Spain.

43. Dobrogowski J, Wordliczek J. Pain in elderly patients. Geriatria. 2002; (12):7-15. Polish

44. Koniarek J, Dudek B, Makowska Z. The Life Orientation Questionnaire. Adaptation of the Sense of Coherence Questionnaire (SOC) by A. Antonovsky. Przegląd Psychologiczny. 1993;36:491-502. Polish.

45. Rosenstiel A, Keefe FJ. The use of coping strategies in chronic low back pain patients: relationship to patient characteristics and current adjustment. Pain. 1983;17(1):33-44.

46. Juczyński Z. Measures in Health Promotion and Health Psychology. Warsaw: Workshop Psychological Tests PTP; 2009:162-166. Polish.

47. World Medical Association. World Medical Association Declaration of Helsinki: ethical principles for medical research involving humans. JAMA. 2013;310(20):2191-2194.

48. Hadjistavropoulos T, Herr K, Turk DC, et al. An interdisciplinary expert consensus statement on assessment of pain in older persons. Clin J Pain. 2007;23(suppl 1):1-43.

49. Sofaer B, Walker J. Mood assessment in chronic pain patents. Disabil Rehabil. 1994;16(1):35-38.

50. Turk DC, Okifuji A, Scharft L. Chronic pain and depression: role of perceived impact and perceived control in different age cohorts. Pain. 1995;61(1):93-101.

51. Walid MS, Zaytseva N. Pain in nursing home residents and correlation with neuropsychiatric discords. Pain Physician. 2009;12(5):877-880.

52. Dunn KS, Horgas AL. Religious and nonreligious coping in older adults experiencing chronic pain. Pain Manag Nurs. 2004;5(1):19-28.

53. Jorgensen RS, Frankowski JJ, Corey MP. Sense of coherence, negative life events and appraisal of physical health among university students. Pers Individ Diff. 1999;27(6):1079-1089.

54. Sanden-Eriksson B. Coping with type-2 diabetes: the role of sense of coherence compared with active management. J Adv Nurs. 2000;31(6): 1393-1397.

55. Thome B, Hellberg IR. Quality of life in older people with cancer a gender perspective. Eur J Cancer Care. 2004;13(2):454-463.

56. Edman L, Larsen J, Hagglund H, Gardulf A. Health-related quality of life, symptom distress and sense of coherence in adult survivors of allogeneic stem-cell transplantation. Eur J Cancer Care. 2001;10(2):124-130.

57. Schnyder U, Moergeli H, Trentz O, Klaghofer R, Buddeberg C. Prediction of psychiatric morbidity in severely injured accident victims at oneyear follow-up. Am J Respir Crit Care Med. 2001;164(4):653-656.

58. McGuire BE, Nicholas MK, Asghari A, Wood BM, Main CJ. The effectiveness of psychological treatments for chronic pain in older adults: cautious optimism and an agenda for research. Curr Opin Psychiatry. 2014;27(5):380-384. 
Clinical Interventions in Aging

\section{Publish your work in this journal}

Clinical Interventions in Aging is an international, peer-reviewed journal focusing on evidence-based reports on the value or lack thereof of treatments intended to prevent or delay the onset of maladaptive correlates of aging in human beings. This journal is indexed on PubMed Central, MedLine,

CAS, Scopus and the Elsevier Bibliographic databases. The manuscript management system is completely online and includes a very quick and fair peer-review system, which is all easy to use. Visit http://www.dovepress. $\mathrm{com} /$ testimonials.php to read real quotes from published authors.

Submit your manuscript here: http://www.dovepress.com/clinical-interventions-in-aging-journal 